\title{
Ovum transport in cyclic rats rendered hypo-oestrogenic by treatment with 4-hydroxy-4-androstene-3,17-dione
}

\author{
M. L. Forcelledo and H. B. Croxatto \\ Laboratorio de Endocrinologia, Departmento de Ciencias Fisiológicas, Pontificia Universidad \\ Católica de Chile, Santiago, Chile
}

\begin{abstract}
Summary. The effects of decreasing oestrogen secretion upon the rate of oocyte transport achieved by the administration of 4-hydroxy-4-androstene-3,17-dione were investigated in cyclic rats. Control animals examined during late pro-oestrus showed that the majority of oocytes had entered the uterus. In contrast, when inhibitor was administered from the afternoon of metoestrus or from late dioestrus through prooestrus, oviducal retention of oocytes was observed. When treatment was delayed until the morning of pro-oestrus, only uterine retention of oocytes was observed. The inhibitor decreased oestradiol concentrations in ovarian vein, while systemic testosterone values were increased. Treatment with exogenous oestradiol counteracted the effect of the inhibitor on ovum transport. The elevation of systemic testosterone concentrations by means of subdermal implants of testosterone failed to alter the normal pattern of ovum transport. These results demonstrate that normal oestrogen secretion during late metoestrus and dioestrus is required for the movement of oocytes from the oviduct to the uterus, whereas the preovulatory oestrogen surge is needed for the expulsion of ova from the uterus.
\end{abstract}

\section{Introduction}

The role of endogenous oestrogens and progestagens in the regulation of ovum transport through the genital tract has been partly elucidated. Different patterns of ovum transport have been correlated with different patterns of endogenous steroid levels (Forcelledo, Vera \& Croxatto, 1981). In cyclic rats, oocytes reach the uterus in about 3 days and are expelled from the genital tract in the following hours while in pregnant rats all ova remain in the oviducts for 4 days and are retained in the uterus (Forcelledo et al., 1981). In comparison with pregnant rats, therefore, cyclic animals show a premature transfer of ova to the uterus and partial failure to retain them in this segment of the tract. This pattern of accelerated ovum transport might be related to absolute and relative increases in oestradiol concentrations during late dioestrus and pro-oestrus in cyclic animals. To test this hypothesis, partial suppression of basal oestradiol secretion and the oestradiol preovulatory surge was attempted. The inhibition of oestradiol synthesis was attained with 4-hydroxy-4-androstene-3,17-dione, an aromatase inhibitor which blocks the conversion of androgens to oestrogens (Brodie, Scharzel, Shaikh \& Brodie, 1977). This compound has been shown to inhibit oestrogen-dependent processes in the rat, such as ovulation, implantation and growth of mammary tumours induced by 7,12-dimethylbenza-anthracene (Brodie et al., 1977).

\section{Materials and Methods}

Sprague-Dawley virgin female rats weighing 180-220 g were used. They were kept in a room with lights on from $07: 00$ to $21: 00 \mathrm{~h}$ at a temperature of about $25^{\circ} \mathrm{C}$. Vaginal smears were taken every 
morning and only animals exhibiting at least two consecutive 4-day cycles were used. The inhibitor (supplied by Dr Angela Brodie, University of Maryland, Baltimore, MD, U.S.A.) was injected s.c. in $0.2 \mathrm{ml}$ olive oil every $4 \mathrm{~h}$ for the periods indicated below. The total daily dose used was $10 \mathrm{mg}$ per day per rat and each injection contained one sixth of the daily dose. Control animals received $0.2 \mathrm{ml}$ vehicle at the same times. Some animals were killed at the end of treatment to determine the number and distribution of oocytes in the genital tract (ovum transport). At this time the presence or absence of ballooning was noted as an indication of oestrogen action. Other animals were used to determine ovarian oestradiol secretion.

\section{Ovum transport}

Rats were randomly assigned to the following groups.

Group 1: 8 rats were treated with inhibitor from 20:00 h on the day of metoestrus until autopsy and 6 control rats were treated with vehicle only. All animals were killed at 16:00 h on the day of pro-oestrus.

Group 2: 12 rats were treated with inhibitor from 16:00 h of dioestrus until autopsy; 13 control rats were treated with vehicle only. They were killed at $16: 00 \mathrm{~h}$ of pro-oestrus.

Group 3: 8 rats treated with inhibitor from $08: 00 \mathrm{~h}$ of pro-oestrus until autopsy and 4 control rats treated with vehicle only were killed at 18:00 h on the day of pro-oestrus.

Group 4: 11 rats at late metoestrus were given s.c. implants with two Silastic (Dow Corning Corporation, Midland, MI, U.S.A.) capsules filled with testosterone (Sigma Chemical Co., St Louis, MO, U.S.A.). Each capsule was $34 \mathrm{~mm}$ long, $0.157 \mathrm{~cm}$ i.d. and $0.317 \mathrm{~cm} \mathrm{o.d.} \mathrm{At} \mathrm{each} \mathrm{end,}$ $2 \mathrm{~mm}$ were sealed with adhesive and the rest was filled with testosterone crystals. Implants were kept under running water for $24 \mathrm{~h}$ before use. Five rats treated with testosterone implants as described above and 5 rats implanted with empty Silastic cylinders were injected with inhibitor from 20:00 h of metoestrus until autopsy; 10 control rats were implanted with empty capsules and injected with vehicle only. All animals were killed at $16: 00 \mathrm{~h}$ on the day of pro-oestrus. At this time blood was collected with a heparinized syringe from the abdominal aorta under ether anaesthesia. Plasma was kept at $-20^{\circ} \mathrm{C}$ until testosterone was assayed.

Group 5: 6 rats were treated with inhibitor from 20:00 h on the day of metoestrus. One Alzet osmotic minipump Model 2001 (Alza Corporation, Palo Alto, CA, U.S.A.) was implanted s.c. at the back of the neck $2 \mathrm{~h}$ earlier. Each pump was filled with $200 \mu \mathrm{l}$ propylene glycol containing $41.6 \mu \mathrm{g}$ oestradiol $/ \mathrm{ml}$ (Sigma) and delivered $1 \mu \mathrm{g}$ oestradiol $/ 24 \mathrm{~h}$. The 6 control rats were injected with inhibitor and implanted with a minipump filled with solvent. At 16:00 h of pro-oestrus the animals were anaesthetized with ether and blood was collected from the abdominal aorta with a heparinized syringe. Plasma was kept at $-20^{\circ} \mathrm{C}$ until oestradiol assay.

Rats from all the above groups were killed by ether inhalation. Oviducts and uterine horns were removed and flushed separately with saline $(9 \mathrm{~g} \mathrm{NaCl} / 1)$. All flushings were examined under low-power magnification to count the ova.

\section{Ovarian oestradiol secretion}

Ten rats treated with inhibitor as in Group 1 were subdivided in two groups of 5 each and were lightly anaesthetized with ether at $12: 00 \mathrm{~h}$ on the day of dioestrus and 16:00 $\mathrm{h}$ of pro-oestrus respectively. Another 6 rats treated with inhibitor as in Group 3 were anaesthetized at 16:00 h of pro-oestrus. In all these animals heparin was injected via the femoral vein. The genital tract was exposed through a ventral midline incision. The uterine vein was ligated and a polyethylene tube was inserted into the ipsilateral ovarian vein. Blood was collected into a centrifuge tube for 6-12 min. The blood and the plasma volume were recorded. The plasma was frozen at $-20^{\circ} \mathrm{C}$ until oestradiol was assayed. To assess the normal pattern of ovarian secretion of oestradiol, 53 cyclic rats were injected with vehicle only using the same protocol used for the experimental animals. 
different days or among treated groups which received the drug on different days (Conover, 1980). Differences in total ova recovered were analysed by the Kruskal-Wallis nonparametric test with multiple comparisons (Conover, 1980). Differences in oestradiol secretion and plasma concentrations of oestradiol and testosterone between treated and control groups were assessed by Student's $t$ test and the Kruskal-Wallis test respectively. Only $P$ values $<0.05$ were considered significant.

\section{Results}

The ovarian secretion rate of oestradiol in control and inhibitor treated rats is shown in Fig. 1. After a peak in late metoestrus, the oestradiol secretion fluctuated at low levels through dioestrus and reached the highest value between 12:00 and 20:00 h of pro-oestrus. Injection of the inhibitor from metoestrus to pro-oestrus (Group 1) decreased significantly $(P<0.05)$ the basal secretion of oestradiol measured at $12: 00 \mathrm{~h}$ of dioestrus $(1334 \pm 324 \mathrm{pg} / \mathrm{h} / \mathrm{ovary} v s 617 \pm 128 \mathrm{pg} / \mathrm{h} / \mathrm{ovary}$; mean \pm s.e.m.; $N=6$ and 5 rats, respectively) and suppressed the pro-oestrous surge of oestradiol (Fig. 1a), at least until the time of examining the number and distribution of oocytes in the genital tract $(4963 \pm 721 \mathrm{pg} / \mathrm{h} /$ ovary vs $354 \pm 84 \mathrm{pg} / \mathrm{h}$ /ovary; mean \pm s.e.m.; $\mathrm{N}=5$ rats each $)$. This surge was also prevented by inhibitor treatment started in the morning of pro-oestrus (Group 3) (Fig. 1b) $(4963 \pm 721 \mathrm{pg} / \mathrm{h} /$ ovary $v s 522 \pm 90 \mathrm{pg} / \mathrm{h} /$ ovary; mean \pm s.e.m.; $\mathrm{N}=5$ and 6 rats, respectively). The average oestradiol secretion on the day of pro-oestrus in inhibitor-treated rats represented $10 \%$ of the control values.

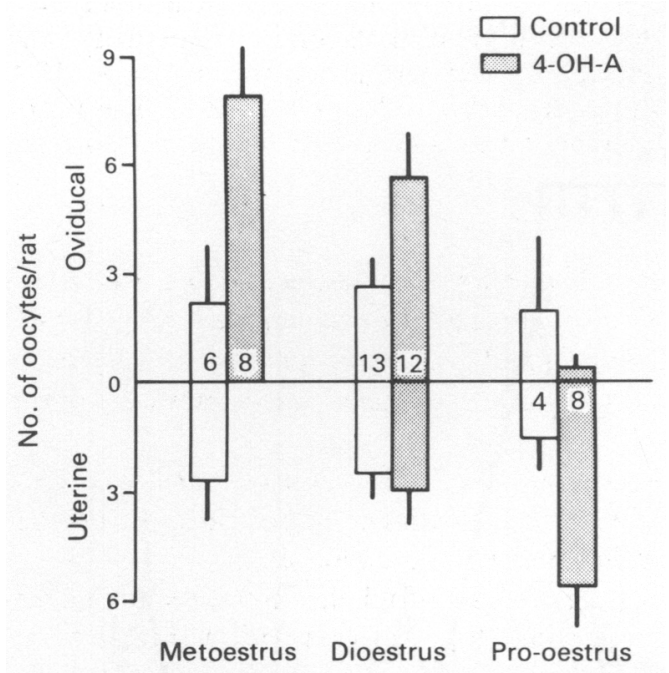

Fig. 2. Effects of 4-OH-androstenedione (4-OH-A) on retention of oocytes in the oviduct and uterus during pro-oestrus. Values are mean \pm s.e.m. for the no. of rats indicated. Injection of the aromatase inhibitor from metoestrus to pro-oestrus produced a significant oviducal retention $(P<0.001)$. Injection of the inhibitor during pro-oestrus produced a significant uterine retention $(P<0.001)$.

The number and distribution of oocytes recovered from the genital tract during late pro-oestrus in inhibitor-treated rats (Groups 1,2 and 3) is shown in Fig. 2. There was no statistically significant difference in the number or distribution of oocytes between the 3 control groups. The number of oocytes was $60-70 \%$ higher in rats injected with the inhibitor $(P<0.05)$. These 3 treated groups differed significantly in the distribution of oocytes between themselves and from their controls. 

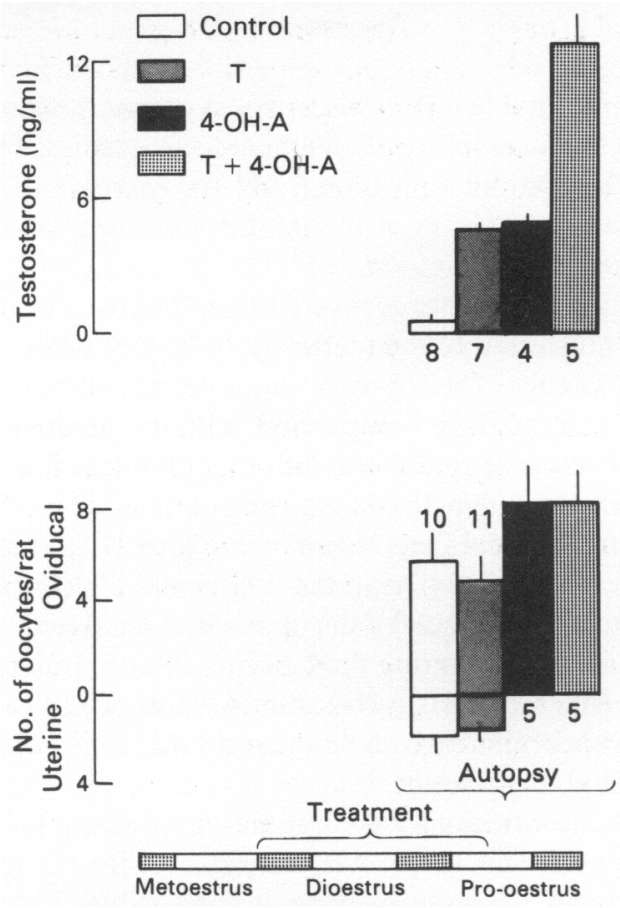

Fig. 3. Effects of testosterone (T) and/or 4-OH-androstenedione (4-OH-A) upon plasma testosterone concentrations and oocyte distribution in pro-oestrous rats. Values are mean \pm s.e.m. for the no. of rats indicated. Testosterone implants and/or 4-OH-A treatment increased testosterone concentrations over control values $(P<0.001)$. The distribution of oocytes in groups that received the inhibitor was different from that in those that did not receive the inhibitor $(P<0.005)$.

Control rats had their ova equally distributed between oviducts and uteri whereas rats treated with inhibitor from metoestrus (Group 1) had all their ova in the oviduct $(P<0.001)$. Rats injected with inhibitor from dioestrus (Group 2) had a larger proportion of oocytes in the oviducts than in the uteri and the reverse was seen in the group treated with inhibitor during pro-oestrus (Group 3 ) $(P<0.001)$.

Ballooning of the uterus was present at $16: 00 \mathrm{~h}$ of pro-oestrus in the majority of control rats and in those treated with inhibitor when treatment began in early pro-oestrus. Rats treated with inhibitor from metoestrus or dioestrus had no ballooning.

Treatment with inhibitor produced a 15 -fold elevation of systemic testosterone concentrations over the values of the control group (Fig. 3). Rats with a similar testosterone elevation due to testosterone implants (Group 4) showed the same number and distribution of oocytes as did control rats with empty implants. Plasma testosterone concentration was further increased when the inhibitor was given in addition to testosterone implants and these rats had the same number and distribution of oocytes as rats treated with the aromatase inhibitor only. No differences were found in total oocyte recovery between these four groups. The only statistically significant difference detected was found in the comparison of oocyte distribution between groups with and without inhibitor.

When oestradiol was given concomitantly with inhibitor (Group 5), the number of oviducal ova dropped from $7.8 \pm 1.6$ (mean \pm s.e.m., $\mathrm{N}=6)$ to zero $(\mathrm{n}=6)(P<0.005)$ and the oestradiol levels increased from $61.4 \pm 5.6(\mathrm{~N}=6)$ to $103 \pm 4.2(\mathrm{~N}=5) \mathrm{pg} / \mathrm{ml}(P<0.005)$. Uterine ballooning was present in half of these rats and it was randomly related to the number of oocytes lost. 


\section{Discussion}

The use of the aromatase inhibitor made it possible to assess ovum transport rates in cyclic rats subjected to a marked decrease in the availability of endogenous oestradiol. The pronounced reduction in oestradiol secretion into the ovarian vein blood and the increase in peripheral plasma testosterone concentrations after administration of the inhibitor confirm the efficacy of this treatment for inhibiting oestrogen synthetase (Brodie et al., 1977).

The number and distribution of oocytes recovered from control rats indicate that a large proportion of oocytes had been transferred to the uterus by 16:00 h of pro-oestrus and that some were presumably lost through the vagina. This observation confirms earlier data showing that ovum transport in cyclic rats is accelerated in comparison with pregnant and pseudopregnant rats (Forcelledo et al., 1981). As a result of treatment with the inhibitor, the transfer of oocytes to the uterus was delayed in rats injected from metoestrus to pro-oestrus. This effect upon ovum transport was partly observed when inhibitor treatment began in late dioestrus. Injection of inhibitor during pro-oestrus prevented the oocytes from entering the uterus and also averted their expulsion from this organ. Expulsion or retention of oocytes by the uterus was unrelated to the presence or absence of ballooning at the time of autopsy. Uterine fluid begins to accumulate around 06:00 h of prooestrus and is retained until 06:00 h of oestrus (Nequin, Alvarez \& Schwartz, 1979). Oocyte expulsion from the uterus of cyclic rats begins early in pro-oestrus (M. L. Forcelledo, unpublished) and is therefore unrelated to the discharge of uterine fluid.

Circulating progesterone concentrations were not measured in the present work. However, the possibility that changes in progesterone values were responsible for the retention of oocytes in the oviduct or uterus are unlikely. A decrease in progesterone values would have effects opposite to those that were actually observed (Forcelledo, Morales, Vera, Quijada \& Croxatto, 1982). Moreover, treatment with the inhibitor does not elevate plasma LH concentrations in the rat (Brodie et al., 1977) and it is therefore unlikely that progesterone secretion was indirectly stimulated.

The changes in ovum transport rate after administration of 4-hydroxy-4-androstene-3,17-dione were the opposite to those produced by an excess of oestrogen in the rat (Ortiz, Villalon \& Croxatto, 1979). This, together with the fact that exogenous oestradiol reversed the effects of the inhibitor and exogenous testosterone did not change the rate of ovum transport, leads to the conclusion that the effects of the inhibitor on the transport of oocytes by the oviduct and uterus can be accounted for entirely by decreased availability of oestrogens. These results show for the first time that endogenous oestrogens at physiological concentrations regulate oocyte transport through the genital tract during the rat oestrous cycle.

This research was supported by Grants DIUC 35/80 and The Rockefeller Foundation RF 83016. We thank Mrs A. Brandeis and Mrs E. Nuñez for the radioimmunoassays.

\section{References}

Brodie, A.M.H., Scharzel, W.C., Shaikh, A.A. \& Brodie, H.Y. (1977) The effect of an aromatase inhibitor, 4-hydroxy-4-androstene-3,17-dione, on estrogendependent processes in reproduction and breast cancer. Endocrinology 100, 1684-1695.

Conover, W.J. (1980) Practical Nonparametric Statistics, 2nd edn. John Wiley \& Sons, New York.

Forcelledo, M.L., Vera, R. \& Croxatto, H.B. (1981) Ovum transport in pregnant, pseudopregnant, and cyclic rats and its relationship to estradiol and progesterone levels. Biol. Reprod. 24, 760-765.

Forcelledo, M.L., Morales, P., Vera, R., Quijada, S. \& Croxatto, H.B. (1982) Role of ovarian and adrenal progesterone in the regulation of ovum transport in pregnant rats. Biol. Reprod. 27, 1033-1041.

Nequin, L.G., Alvarez, J. \& Schwartz, N.B. (1979) Measurement of serum steroid and gonadotropin levels and uterine and ovarian variables throughout 4 day and 5 day estrous cycles in the rat. Biol. Reprod. 20, 659-670.

Ortiz, M.E., Villalón, M. \& Croxatto, H.B. (1979) Ovum transport and fertility following postovulatory treatment with estradiol in rats. Biol. Reprod. 21, $1163-1167$

Received 1 May 1985 